\title{
Complex Anal Fistula: Long-Term Results of Modified Ligation of Intersphincteric Fistula Tract=LIFT
}

\author{
(1) Mustafa Fevzi Celayir, (1) Emre Bozkurt, (1) Nurcihan Aygun, (1) Mehmet Mihmanli \\ Department of Surgery, Sisli Hamidiye Etfal Traning and Research Hospital, Istanbul, Turkey
}

\begin{abstract}
Objectives: The anal fistula is a permanent infectious tunnel formed between the anal canal and skin in the perianal region. Fistulas are treated by surgery at any stage. Many surgical methods have been reported to treat anal fistula. One of the promising surgical methods with a high success rate is ligation of the intersphincteric fistula tract, which is performed in anatomical spaces without damage to the internal and external sphincters. We evaluated the success rate of a modified ligation of the intersphincteric fistula tract procedure for complex anal fistulas in which the technical differences were minimized by the surgery being performed by the same surgical team.

Methods: In this study, Data of the 56 patients were retrospectively collected. Data regarding patient history, visual and digital anal examination, Cleveland Clinic Florida Fecal Incontinence (CCF-FI) score, anal-phase pelvic magnetic resonance imaging (MRI), rectosigmoidoscopy or colonoscopy and anal manometry were recorded. The changes in data recorded during the preoperative and postoperative periods were compared in each other.

Results: The mean age of the patients was $41 \pm 15.5$ years. The number of patients for each fistula type compromised in this study was as follows in accordance with frequency: high transsphincteric fistula, high intersphincteric fistula, and horseshoe abscess. The fistula recurred in seven patients during postoperative follow-up and the success rate of modified LIFT was calculated as $87.5 \%$. The change in the mean \pm SD preoperative and postoperative CCF-FI scores and anal pressure was not statistically significant.

Conclusion: One promising advantage of the ligation of the intersphincteric fistula tract procedure is that it turns a complex fistula into a simple fistula that can be treated with minimal risk of sphincter damage.

Keywords: Anal fistula; complex anal fistula; lift; ligation of the intersphincteric fistula tract.

Please cite this article as "Celayir MF, Bozkurt E, Aygun N, Mihmanli M. Complex Anal Fistula: Long-Term Results of Modified Ligation of Intersphincteric Fistula Tract=LIFT. Med Bull Med Bull Sisli Etfal Hosp 2020;54(3):297-301".
\end{abstract}

T he anal fistula is a permanent infectious tunnel formed between the anal canal and skin in the perianal region. Abscesses and anal fistulas constitute approximately $70 \%$ of the suppurative diseases of the perianal region. ${ }^{[1]}$ Perianal abscesses have a nearly $40 \%$ chance of causing a perianal fistula. ${ }^{[2]}$ Perianal fistulas occur mostly after perianal abscess drainage due to cryptoglandular drainage. Crohn's disease, trauma, radiation exposure, or malignancy also can be underlying causes. ${ }^{[3]}$ Zanotti et al. ${ }^{[4]}$ reported that the incidence of fistula in the European Union varies between 1.20 and $2.80 / 10.000$ people per year, according to data from four European countries.

According to the Parks classification, anal fistulas are divided into four main groups: ${ }^{[5]}$ (i) intersphincteric (extension of the abscess in the intersphincteric plane to the anal edge): (ii) transsphincteric (starts from the intersphincteric area,

Address for correspondence: Mustafa Fevzi Celayir, MD. Sisli Hamidiye Etfal Egitim ve Arastirma Hastanesi, Cerrahi Klinigi, Istanbul, Turkey Phone: +90 5322418245 E-mail: fcelayir@gmail.com

Submitted Date: June 09, 2020 Accepted Date: June 26, 2020 Available Online Date: August 24, 2020

${ }^{\circ}$ Copyright 2020 by The Medical Bulletin of Sisli Etfal Hospital - Available online at www.sislietfaltip.org

OPEN ACCESS This is an open access article under the CC BY-NC license (http://creativecommons.org/licenses/by-nc/4.0/). 
through the external sphincter, to the ischiorectal fossa, and then opening to the perianal skin-a small part of the external sphincter is affected); (iii) suprasphincteric (starts from the intersphincteric space and passes over the external sphincter and puborectal muscle); and (iv) extrasphincteric fistulas (reaches the rectal wall through the perineal skin, fat of the ischiorectal, and levator ani muscles). The incidence of fistulas, according to subtype, is 50\%, 30\%, $15 \%$, and $5 \%$, respectively. Fistulas are treated by surgery at any stage. However, possible sphincter damage may make decision-making difficult.

Transsphincteric, suprasphincteric, and extrasphincteric fistulas are called complicated fistulas and are treatment-resistant diseases of general surgery due to the recurrence rate. Many surgical methods (fistulotomies, fistulectomies, seton application, rectal advancement flap, fibrin glue, and collagen plugs) have been reported. ${ }^{[6]}$ No procedure for perianal fistula treatment has definitively been superior to others, and searches for new treatment methods have been ongoing due to the low success rate of the reported methods. In 2007, Rojanasakul et al. ${ }^{[7]}$ reported a new sphincter-preservation technique called ligation of the intersphincteric fistula tract (LIFT), which is performed in anatomical spaces without damage to the internal and external sphincters. A $94 \%$ success rate with no change in continence was observed in 18 patients. Given these promising initial results, the LIFT procedure has gained great popularity among surgeons. In contrast, success rates are lower in the current experience. Various surgeons have reported a decreased recovery rate by up to $57 \%{ }^{[8]}$ The fact that such a difference in success rates exists is due to the lack of homogenization of patients. The most common cause of recurrent fistulas is a poorly drained collection, especially in the supralevator region. In case of relapse, various factors, such as abscess, local sepsis, when the tract is not mature enough for transection, the need for seton placement before LIFT, or the presence of a fistula tract longer than $3 \mathrm{~cm}$, also may affect the success. ${ }^{[9-11]}$

We evaluated the success rate of a modified LIFT procedure for complex anal fistulas in which the technical differences were minimized by the surgery being performed by the same surgical team.

\section{Methods}

\section{Study Protocol}

We retrospectively collected data for 56 patients who underwent a modified LIFT for a complex anal fistula between January 2013 and January 2018. The study protocol was approved by the local institutional review board of the University of Health Sciences Sisli Hamidiye Etfal Education and Research Hospital (approval code: 1394). This study was conducted in accordance with the tenets of the 1964 Declaration of Helsinki. Written, informed consent was obtained from all subjects before participation, and all methods were performed in accordance with the relevant guidelines and regulations of our institutional review board.

Patient history, visual and digital anal examination, Cleveland Clinic Florida Fecal Incontinence (CCF-FI) score, analphase pelvic magnetic resonance imaging (MRI), and rectosigmoidoscopy or colonoscopy were performed for diagnostic purposes. In particular, MRI was used to classify anal fistula, while endoscopy was used for the differential diagnosis of inflammatory bowel diseases. Inclusion criteria were age $>18$ years, diagnosis of complex anal fistula, and patients without intersphincteric fistula on MRI and who provided consent for the LIFT operation. Patients diagnosed with inflammatory bowel disease and malignancy, as well as patients who did not provide consent for LIFT, were excluded from this study.

All surgical procedures were performed with the patient under the prone jack-knife position after approval for spinal anesthesia. With the guidance of MRI, the internal orifice was revealed with a metallic probe inserted through the fistula tract outer orifice. When the internal orifice was not clearly seen, we injected hydrogen peroxide from the external orifice to locate the internal orifice. After a perineal incision was made from the projection of the intersphincteric space and the fistula tract was exposed, the tract was grasped with a right-angle forceps and released from adjacent structures (Fig. 1a). The tract was ligated with 2-0 Vicryl CR SH-1 (Ethicon, Inc., Somerville, NJ, USA) from two distant points at least $1 \mathrm{~cm}$ away from each other and divided, and this segment was excised (Fig. 1b). The external orifice was cauterized without tract occlusion to not block the drainage. Patients were advised to eat a variety of fiber-rich foods and drink plenty of fluids. All patients were discharged one day postoperatively and were advised to use sitz baths twice a day.

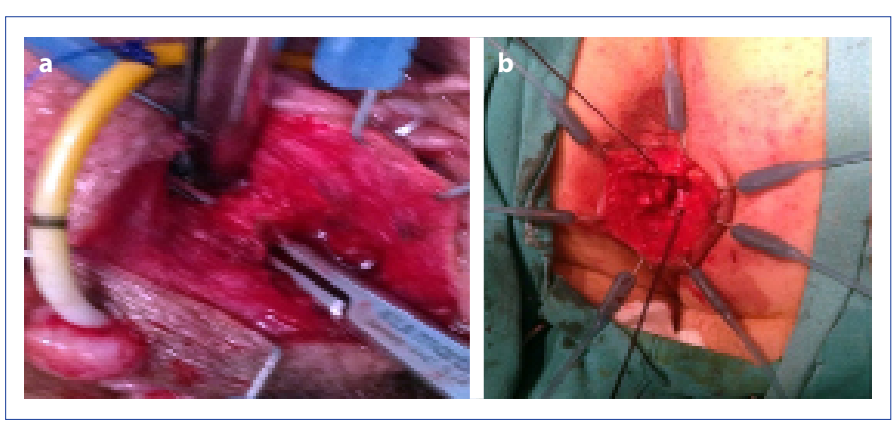

Figure 1. (a) Hanging of tract with the right angle, (b) Ligation of tract with the 2/0 Vicryl CR SH-1 (Ethicon). 
Data regarding patient follow-up at two weeks and 1, 3, 6, 9,12 , and 15 months were recorded. Patients with recurrent complaints the same as during the preoperative period and purulent drainage from the external fistula tract orifice were considered to have failed the treatment. The CCF-FI scale was applied in all patients preoperatively and at six months postoperatively. ${ }^{[12]}$ The scale was scored according to the frequency and type of incontinence (solid stool, fluid, gas, pad use, and its effect on daily life; Table 1). Mild, moderate, and severe incontinence was scored as $\leq 8,9-14$, and $15-20$, respectively. Patients with a score $>9$ underwent anal manometry evaluation.

\section{Statistical Analysis}

All statistical analysis was performed using SPSS version 19.0 (SPSS, Inc., Chicago, IL, USA). Data for continuous variables were reported as means \pm standard deviation (SD). Median, minimum, and maximum categorical variables were presented as numbers and percentages. Categorical variables were compared using the $x^{2}$ test, and continuous variables were compared using the Student's t-test for normal distribution or the Mann-Whitney $U$ test for non-normal distribution. The Wilcoxon signed-rank test was used to analyze the CCF-FI score difference between baseline and follow-up. $\mathrm{P}<0.05$ was considered statistically significant.

\section{Results}

A total of 56 patients ( 37 male, 19 female; mean age, $41 \pm 15.5$ years) diagnosed with complex anal fistula were included in this study and underwent the modified LIFT technique, of which $33(58.92 \%)$ patients had a high transsphincteric fistula, 22 (39.3\%) patients a high intersphincteric fistula, and one $(1.78 \%)$ patient a horseshoe abscess. The etiology of the fistula was a history of perianal abscess drainage in seven (12.5\%) patients. Seven (12.5\%) patients had an anteriorly located external fistulous orifice. The length of the fistula tracts ranged from 1.5 to $9 \mathrm{~cm}(3.54 \pm 1.46)$. Because

Table 1. Cleveland Clinic Florida Fecal Incontinence ${ }^{[12]}$

\begin{tabular}{lccccc}
\hline \multirow{2}{*}{ Type of incontinence } & \multicolumn{5}{c}{ Frequency } \\
\cline { 2 - 6 } & Never & Rarely & Sometimes & Usually Always \\
\hline Solid & 0 & 1 & 2 & 3 & 4 \\
Liquid & 0 & 1 & 2 & 3 & 4 \\
Gas & 0 & 1 & 2 & 3 & 4 \\
Wears pad & 0 & 1 & 2 & 3 & 4 \\
Lifestyle alteration & 0 & 1 & 2 & 3 & 4 \\
\hline
\end{tabular}

$0=$ perfect; $20=$ complete incontinence; Never $=0$; Rarely $=<1 /$ month; Sometimes $=<1 /$ week, $\geq 1 /$ month; Usually $=<1 /$ day, $\geq 1$ /week; Always $=$ $\geq 1 /$ day. of active infection, a seton was placed for drainage in three patients (5.35\%) preoperatively (Table 2 ).

The fistula recurred in seven patients during postoperative follow-up (median relapse time, six months). Six of the recurrent fistulas became intersphincteric fistulas and were treated with fistulotomy, and one patient was treated with repeat LIFT.

Mean \pm SD preoperative and postoperative 6-month CCF-FI scores were 11.2 \pm 4.7 and 10.3 \pm 3.8 , respectively. Particular improvement was detected regarding the CCF-FI score, but there was no statistically significant difference. Table 3 shows the data regarding mean \pm SD resting and maximal anal pressures before and after LIFT. The change in anal pressures during postoperative follow-up also was not statistically significant.

\section{Discussion}

In our study, 61 LIFT procedures were performed in 56 patients. Four patients were treated with nine lifts (two transsphincteric fistulas in three patients each and three transsphincteric fistulas in one patient). During the 12-month follow-up of these LIFT patients with complicated anal fistula, the anal fistula recurred in seven patients, but the fistulas were not complicated and all were intersphincteric fistulas. Many factors affect the healing rate of anal fistulas,

Table 2. Demographics and characteristics of the patients

\begin{tabular}{lc}
\hline Sex $(n, \%)$ & \\
Male & $37,66.07$ \\
Female & $19,32.93$ \\
Age (mean \pm SD) year & $41 \pm 15.5$ \\
Fistula type (n, \%) & \\
$\quad$ High transsphincteric & $33(58.92)$ \\
$\quad$ High intersphincteric & $22(39.3)$ \\
$\quad$ Horseshoe abscess & $1(1.78)$ \\
Length of fistule tract cm (n, \%) (min-max) & $3.54 \pm 1.46(1.5-9)$ \\
Preoperative seton application $(n, \%)$ & $3(5.35)$ \\
History of abscess drainage $(n, \%)$ & $7(12.5)$ \\
Recurrence $(n, \%)$ & $7(12.5)$ \\
\hline
\end{tabular}

Table 3. Anal manometer during preoperative period and postoperative $6^{\text {th }}$ month

\begin{tabular}{|c|c|c|c|}
\hline & Preoperative & $\begin{array}{c}\text { Postoperative } 6^{\text {th }} \\
\text { month }\end{array}$ & $\mathbf{p}$ \\
\hline $\begin{array}{l}\text { Resting anal pressure } \\
\mathrm{mmHg} \text { (mean } \pm \mathrm{SD} \text { ) }\end{array}$ & $54.7 \pm 13.3$ & $52.1 \pm 12.6$ & NS \\
\hline $\begin{array}{l}\text { Maximal anal pressure } \\
\mathrm{mmHg}(\operatorname{mean} \pm \mathrm{SD})\end{array}$ & $119.76 \pm 23.4$ & $117.81 \pm 21.2$ & NS \\
\hline
\end{tabular}

NS: non-significant. 
such as the anatomic complexity of the original fistula, unnecessary manipulation of the operative field, comorbidities, surgeon's experience with LIFT, and previous operations. ${ }^{[13]}$

Many studies have reported on factors affecting the success of the procedure. Tan et al. ${ }^{[14]}$ stated that if the LIFT incision is small and deep, blood or effusion may accumulate and increase the possibility of postoperative infection and wound dehiscence. Van Onkelen et al. ${ }^{[15]}$ suggested that an infection may result from inadequate fistula tract ligation at the side of the internal anal sphincter. Also, Khadia et al. ${ }^{[16]}$ stated that if the fistula tract is too thin, deep, or thick, it also may lead to unsuccessful ligation and cause recurrence. In our study, we grasped the fistula tract with a right-angle forceps; after releasing it from all attachments, we sutured and ligated the tract with 2-0 Vicryl CR SH-1 from two distant points at least $1 \mathrm{~cm}$ away from each other. In this way, the two ends of the fistula tract did not remain open.

Liu et al. ${ }^{[17]}$ found that the length of the fistula was inversely proportional to the cure rate of LIFT surgery. The longer the fistula, the more permanent residual epithelialization and necrotic tissue residues have increased the chance of infection, resulting in difficult treatment and recurrence risk. They chose $3 \mathrm{~cm}$ as a cutoff and stated that a fistula tract $<3 \mathrm{~cm}$ had a significantly high rate of healing. In our study, the mean \pm SD length of the fistula tract was $3.54 \pm 1.46 \mathrm{~cm}$ and the success rate was $87.5 \%$. In 2009, Rojanasaku[ ${ }^{[18]}$ reported a $94 \%$ success rate. Despite this high success rate, studies have reported success ranging from $57 \%$ to $77 \% .{ }^{[19,}{ }^{20]}$ Although the success rate is relatively low, it is within acceptable limits compared to other treatment methods.

The LIFT procedure has been performed in different variations with the same basic principles in the literature since its initial report. As there is no comparison between technical variations of LIFT, determining which variation is superior to others is difficult. Bastawrous et al. ${ }^{[21]}$ performed a modified LIFT in which they ligated the fistula tract from the external sphincter level and performed fistulotomy through the internal sphincter. Unlike traditional LIFT surgery, the success rate with this method, where they removed some of the internal sphincters, was $71.42 \%$. We used one variation of the original procedure in which we sutured and ligated the tract with 2-0 Vicryl CR SH-1 from two distant points at least $1 \mathrm{~cm}$ away from each other.

It is clear that the literature results have proved the successful effectiveness of the LIFT. Especially regarding correct patient choices and operations using the correct technique, the success rates have increased, just like in our series.

\section{Conclusion}

In conclusion, fistulas can be treated with curettage of the fistula tract, local silver nitrate applications, and local incision and drainage for underlying abscess along with antibiotics in case of treatment failure. One promising advantage of the LIFT procedure is that it turns a complex fistula into a simple fistula that can be treated with minimal risk of sphincter damage.

\section{Disclosures}

Ethics Committee Approval: This study started with approval of code 1394 (14/01/2020) by Şişli Hamidiye Etfal Training and Research Hospital Ethics Committee of Clinical Investigations.

Peer-review: Externally peer-reviewed.

Conflict of Interest: None declared.

Authorship Contributions: Concept - M.F.C.; Design - E.B.; Supervision - M.M.; Materials - E.B., M.F.C.; Data collection \&/or processing - E.B., N.A.; Analysis and/or interpretation - M.F.C.; Literature search - M.F.C.; Writing - M.F.C.; Critical review - M.M.

\section{References}

1. Tomiyoshi SD, Dos Santos CH. Effectiveness of the ligation of intersphincteric fistula tract (LIFT) in the treatment of anal fistula: initial results. Arq Bras Cir Dig 2014;27:101-3. [CrossRef]

2. Abcarian H. Anorectal infection: abscess-fistula. Clin Colon Rectal Surg 2011;24:14-21. [CrossRef]

3. Abcarian AM, Estrada JJ, Park J, Corning C, Chaudhry V, Cintron J, et al. Ligation of intersphincteric fistula tract: early results of a pilot study. Dis Colon Rectum 2012;55:778-82. [CrossRef]

4. Zanotti C, Martinez-Puente C, Pascual I, Pascual M, Herreros D, García-Olmo D. An assessment of the incidence of fistula-in-ano in four countries of the European Union. Int J Colorectal Dis 2007;22:1459-62. [CrossRef]

5. Parks AG, Gordon PH, Hardcastle JD. A classification of fistula-in-ano. Br J Surg 1976;63:1-12. [CrossRef]

6. Wong $\mathrm{S}$, Solomon $\mathrm{M}$, Crowe $\mathrm{P}$, Ooi K. Cure, continence and quality of life after treatment for fistula-in-ano. ANZ J Surg 2008;78:67582. [CrossRef]

7. Rojanasakul A, Pattanaarun J, Sahakitrungruang C, Tantiphlachiva K. Total anal sphincter saving technique for fistula-in-ano; the ligation of intersphincteric fistula tract. J Med Assoc Thai 2007;90:581-6.

8. Hong KD, Kang S, Kalaskar S, Wexner SD. Ligation of intersphincteric fistula tract (LIFT) to treat anal fistula: systematic review and meta-analysis. Tech Coloproctol 2014;18:685-91. [CrossRef]

9. Limura E, Giordano P. Modern management of anal fistula. World J Gastroenterol 2015;21:12-20. [CrossRef]

10. Meinero P, Mori L. Video-assisted anal fistula treatment (VAAFT): a novel sphincter-saving procedure for treating complex anal fistulas. Tech Coloproctol 2011;15:417-22. Erratum in: Tech Coloproc- 
tol 2012;16:111. [CrossRef]

11. Mendes CR, Ferreira LS, Sapucaia RA, Lima MA, Araujo SE. Video-assisted anal fistula treatment: technical considerations and preliminary results of the first Brazilian experience. Arq Bras Cir Dig 2014;27:77-81. [CrossRef]

12. Jorge JM, Wexner SD. Etiology and management of fecal incontinence. Dis Colon Rectum 1993;36:77-97. [CrossRef]

13. Xu Y, Tang W. Ligation of Intersphincteric Fistula Tract Is Suitable for Recurrent Anal Fistulas from Follow-Up of 16 Months. Biomed Res Int 2017;2017:3152424. [CrossRef]

14. Tan KK, Tan IJ, Lim FS, Koh DC, Tsang CB. The anatomy of failures following the ligation of intersphincteric tract technique for anal fistula: a review of 93 patients over 4 years. Dis Colon Rectum 2011;54:1368-72. [CrossRef]

15. van Onkelen RS, Gosselink MP, Schouten WR. Ligation of the intersphincteric fistula tract in low transsphincteric fistulae: a new technique to avoid fistulotomy. Colorectal Dis 2013;15:587-91.
16. Khadia M, Muduli IC, Das SK, Mallick SN, Bag L, Pati MR. Management of Fistula-In-Ano with Special Reference to Ligation of Intersphincteric Fistula Tract. Niger J Surg 2016;22:1-4. [CrossRef]

17. Liu WY, Aboulian A, Kaji AH, Kumar RR. Long-term results of ligation of intersphincteric fistula tract (LIFT) for fistula-in-ano. Dis Colon Rectum 2013;56:343-7. [CrossRef]

18. Rojanasakul A. LIFT procedure: a simplified technique for fistula-in-ano. Tech Coloproctol 2009;13:237-40. [CrossRef]

19. Bleier Jl, Moloo H, Goldberg SM. Ligation of the intersphincteric fistula tract: an effective new technique for complex fistulas. Dis Colon Rectum 2010;53:43-6. [CrossRef]

20. Shanwani A, Nor AM, Amri N. Ligation of the intersphincteric fistula tract (LIFT): a sphincter-saving technique for fistula-in-ano. Dis Colon Rectum 2010;53:39-42. [CrossRef]

21. Bastawrous A, Hawkins M, Kratz R, Menon R, Pollock D, Charbel $J$, et al. Results from a novel modification to the ligation intersphincteric fistula tract. Am J Surg 2015;209:793-8. [CrossRef] 